\title{
BEAM LOSS AND COLLIMATION IN THE FERMILAB 16 GEV PROTON DRIVER*
}

\begin{abstract}
A high beam power of $1.15 \mathrm{MW}$ in the proposed $16-\mathrm{GeV}$ Proton Driver [1] implies serious constraints on beam losses in the machine. The main concerns are the hands-on maintenance and ground-water activation. Only with a very efficient beam collimation system can one reduce uncontrolled beam losses to an allowable level. The results on tolerable beam loss and on a proposed beam collimation system are summarized in this paper. A multi-turn particle tracking in the accelerator defined by all lattice components with their realistic strengths and aperture restrictions, and halo interactions with the collimators is done with the STRUCT code [2]. Full-scale Monte Carlo hadronic and electromagnetic shower simulations in the lattice elements, shielding, tunnel and surrounding dirt with realistic geometry, materials and magnetic field are done with the MARS 14 code [3]. It is shown that the proposed 3-stage collimation system, allows localization of more than $99 \%$ of beam loss in a special straight section. Beam loss in the rest of the accelerator is $0.2 \mathrm{~W} / \mathrm{m}$ on average.
\end{abstract}

A. I. Drozhdin ${ }^{\dagger}$, O. E. Krivosheev, N. V. Mokhov, FNAL, Batavia, IL 60510, USA

\section{TOLERABLE BEAM LOSS}

To determine tolerable beam loss, MARs 14 simulations are done in the arc cells. Regulatory requirements [4] are taken as the limits to be met. A detailed lattice description with dipoles, quadrupoles and long bare beam pipes has been implemented into a 3-D model with corresponding materials and magnetic field distributions (see Fig. 1). A $16-\mathrm{GeV}$ proton beam is assumed to be lost on a beam pipe at a grazing angle of $1 \mathrm{mrad}$ inward. It is distributed uniformly along the arc lattice. Results are normalized per $1 \mathrm{~W} / \mathrm{m}$ beam loss rate, that corresponds to $3.9 \times 10^{8} \mathrm{p} /(\mathrm{m} \cdot \mathrm{sec})$. In this simplified model, a round $2-\mathrm{m}$ radius tunnel with the beam line in the center is assumed with a $0.4-\mathrm{m}$ concrete wall followed by a NuMI-like dirt [4]. The later, probably, gives the worst-case situation for ground-water activation. The allowable losses can be noticeably higher in dolomite or the Fermilab Booster location. Dose accumulated in the hottest spots of the coils, residual dose rates on the outer surface of the lattice elements after 30 days of irradiation and 1 day of cooling, and ground-water activation and dose attenuation in the surrounding dirt are calculated.

Maximum residual dose rates calculated for the arc elements at $1 \mathrm{~W} / \mathrm{m}$ uniform beam loss are shown in the third column of Tab. 1. The table gives also the peak dose accumulated in the coils and the parameter $C_{t o t}$ calculated according to [4]. The last column gives correspond-

\footnotetext{
* Work supported by the Universities Research Association, Inc., under contract DE-AC02-76CH03000 with the U. S. Department of Energy.

† drozhdin@fnal.gov
}

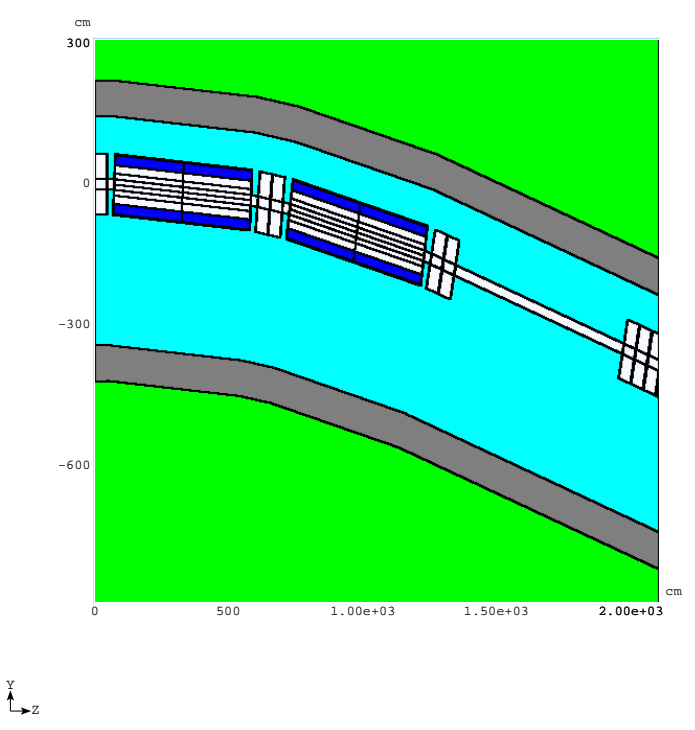

Figure 1: A fragment of the MARS model of the arc.

ing beam loss rates calculated to meet the limits of [4]: $P_{\gamma}=100 \mathrm{mrem} / \mathrm{hr}, D=20 \mathrm{Mrad} / \mathrm{yr}$ and $C_{t o t}=1$. The dose near the bare beam pipes exceeds the design goal for hot regions of $100 \mathrm{mrem} / \mathrm{hr}$; it is noticeably lower near the magnets due to significant absorption of soft photons in the dipole and quadrupole materials. One sees that hands-on maintenance is a serious issue with about $3 \mathrm{~W} / \mathrm{m}$ as a tolerable maximum beam loss rate in the lattice elements, except for the long bare beam pipes where one should decrease the loss rate to $0.25 \mathrm{~W} / \mathrm{m}$ to reduce the dose to $100 \mathrm{mrem} / \mathrm{hr}$. One needs further reduction to bring the dose down to a good practice value of about $10-20 \mathrm{mrem} / \mathrm{hr}$. Alternatively, one can think of providing simple shielding around the bare beam pipes. For ground-water activation $C_{t o t}=0.975$ immediately outside the $40-\mathrm{cm}$ tunnel wall, that allows $1.03 \mathrm{~W} / \mathrm{m}$ beam loss rate. The peak accumulated dose in the coils is about $2 \mathrm{Mrad} / \mathrm{yr}$ at $1 \mathrm{~W} / \mathrm{m}$ beam loss rate.

Table 1: Peak residual dose $P_{\gamma}$ on lattice elements, dose $D$ in the coils, parameter $C_{t o t}$ and allowable beam loss.

\begin{tabular}{|c|l|c|c|}
\hline Value & Element & $\begin{array}{c}\text { Peak } \\
\text { at 1 W/m }\end{array}$ & $\begin{array}{c}\text { Allowable } \\
\text { loss (W/m) }\end{array}$ \\
\hline \multirow{3}{*}{$P_{\gamma}$} & Long pipe & 400 & 0.25 \\
$(\mathrm{mrem} / \mathrm{hr})$ & Quad side & 9.4 & 10.6 \\
& Quad flange & 34 & 2.94 \\
& Dipole side & 5 & 20 \\
& Dipole flange & 20 & 5 \\
\hline$D(\mathrm{Mrad} / \mathrm{yr})$ & Coil & 2 & 10 \\
\hline$C_{\text {tot }}$ & Ground water & 0.98 & 1.03 \\
\hline
\end{tabular}




\section{COLLIMATION SYSTEM}

Assuming that $1 \%$ of the beam is lost at the top accelerator energy, this amounts to $11.5 \mathrm{~kW}$ of power distributed around the ring with a peak loss of up to $3 \mathrm{~kW} / \mathrm{m}$ on several quadrupoles. This level is about 3000 times higher of that which can be accepted in the arcs. The purpose of the beam halo cleaning system is to localize proton losses in a specially shielded short section, thus to reduce irradiation of the rest of the machine to the acceptable levels.

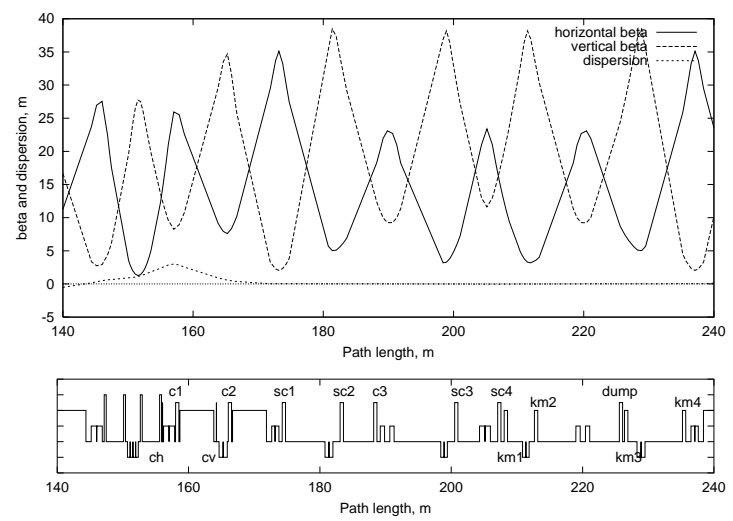

Figure 2: Beta functions and dispersion in the utility section.

There are three 64-meter long straight sections in the Proton Driver [1]. One of them, together with $17 \mathrm{~m}$ of preceding arc, is used for beam injection and collimation (Fig. 2). A collimation system consists of primary, secondary and supplementary collimators (Tab. 2) located in the first $50 \mathrm{~m}$ of this region.

Table 2: $\beta$-functions, dispersion and phase advance between the primary and secondary collimators.

\begin{tabular}{|l|c|c|c|c|}
\hline Collimator & $\begin{array}{c}\beta \text {-function } \\
(\mathrm{m})\end{array}$ & $\begin{array}{c}\text { Disper- } \\
\text { sion } \\
(\mathrm{m})\end{array}$ & \multicolumn{2}{|c|}{$\begin{array}{c}\text { Phase } \\
\text { advance } \\
(\mathrm{deg})\end{array}$} \\
\hline & hor./vert. & & hor. & vert. \\
\hline Hor. primary CH & $19.7 / 10.0$ & 2.8 & 0 & - \\
Secondary C1 & $24.8 / 10.4$ & 2.8 & 5 & - \\
Vert.primary CV & $8.4 / 31.7$ & 0.8 & - & 0 \\
Secondary C2 & $9.6 / 30.7$ & 0.4 & 45 & 4 \\
Supplement. SC1 & $30.3 / 3.8$ & 0.0 & 69 & 100 \\
Supplement. SC2 & $6.9 / 31.5$ & 0.0 & 125 & 140 \\
Secondary C3 & $20.0 / 12.4$ & 0.0 & 152 & 156 \\
Supplement. SC3 & $7.3 / 30.0$ & 0.0 & 253 & 198 \\
Supplement. SC4 & $15.7 / 19.1$ & 0.0 & 279 & 221 \\
\hline
\end{tabular}

The secondary collimators are located with a small offset with respect to the primary ones, at an optimal phase advances for particles interception during the first turn after interaction with the primary collimators (Fig. 3). It is assumed that $10 \%$ of intensity is lost at injection, and $1 \%$ at the top energy.

Tab. 3 summarizes results of the collimation system optimization. Secondary collimators generate out-scattered particles lost later in the lattice. One can reduce this component with supplementary collimators placed farther from the beam to catch particles out-scattered from the secondary ones. We found that optimal thickness of tungsten primary collimators is $1 \mathrm{~mm}$ and length of secondary and supple-
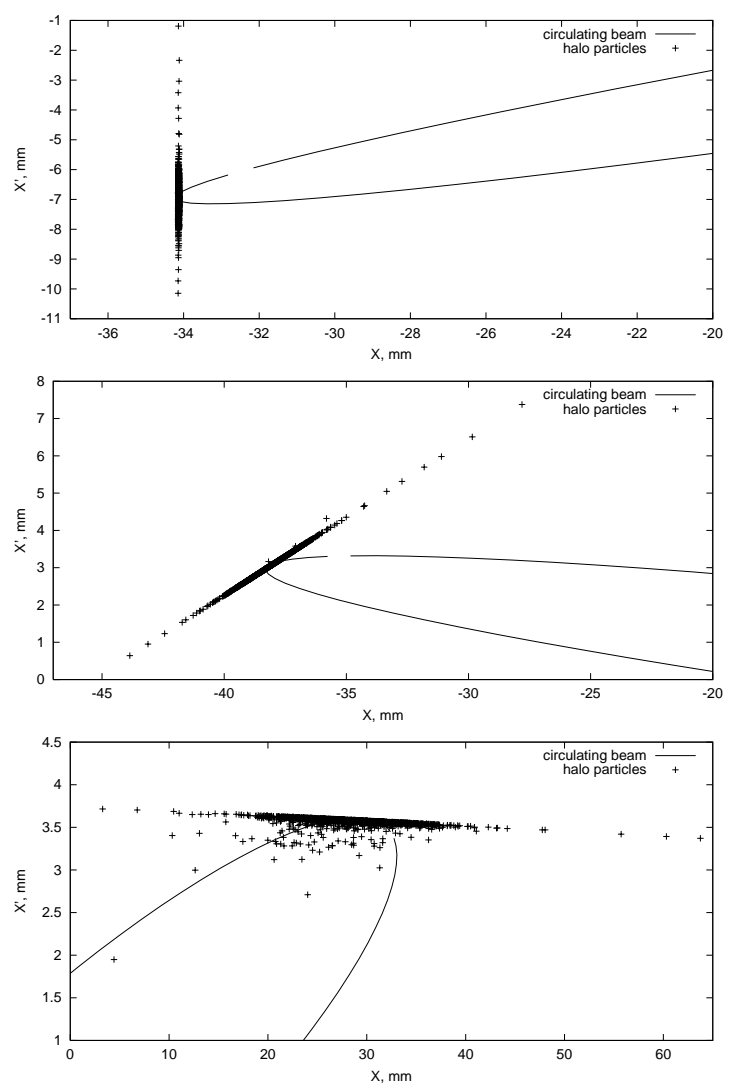

Figure 3: Horizontal phase plane at the primary collimator (top), secondary collimator $\mathrm{C} 1$ (middle), and collimator $\mathrm{C} 3$ (bottom).

mentary stainless steel collimators is $0.5 \mathrm{~m}$. The $\beta$-function varies along the length of a secondary collimator, therefore the collimator jaws are assumed to be aligned with respect to the beam envelope after the painting. Beam loss distribution at the top energy is shown in Fig. 4.

Table 3: Beam loss in the Proton Driver.

\begin{tabular}{|c|c|c|c|}
\hline & \multicolumn{3}{|c|}{ Beam loss } \\
\hline \multirow[t]{2}{*}{ Collimation system } & $\begin{array}{l}\text { Collimation } \\
\text { region }\end{array}$ & $\begin{array}{l}\text { Rest of the } \\
\text { ring }\end{array}$ & $\begin{array}{l}\text { Peak loss rate } \\
\text { in the ring }\end{array}$ \\
\hline & $\mathrm{kW}$ & $\mathrm{kW}$ & $\mathrm{W} / \mathrm{m}$ \\
\hline \multicolumn{4}{|c|}{ AT THE TOP ENERGY $\left(E_{k i n}=16 \mathrm{GeV}\right)$} \\
\hline No collimators & 0.470 & 11.050 & 2700 \\
\hline three secondary at $2 \mathrm{~mm}$ & 11.375 & 0.146 & 13.2 \\
\hline $\begin{array}{l}\text { three secondary at } 2 \text { and } 3 \mathrm{~mm} \\
\text { five supplementary at } 5 \mathrm{~mm}\end{array}$ & 11.449 & 0.071 & 6.7 \\
\hline $\begin{array}{l}\text { with bump } \\
\text { three secondary at } 2 \text { and } 3 \mathrm{~mm} \\
\text { five supplementary at } 5 \mathrm{~mm}\end{array}$ & 11.487 & 0.033 & 4.7 \\
\hline \multicolumn{4}{|c|}{ AT INJECTION $\left(E_{k i n}=0.4 \mathrm{GeV}\right)$} \\
\hline $\begin{array}{l}\text { three secondary at } 2 \text { and } 3 \mathrm{~mm} \\
\text { five supplementary at } 5 \mathrm{~mm}\end{array}$ & 2.879 & 0.001 & 0.2 \\
\hline $\begin{array}{l}\text { at RF capture loss } \\
\text { three secondary at } 2 \text { and } 3 \mathrm{~mm} \\
\text { five supplementary at } 5 \mathrm{~mm}\end{array}$ & 2.877 & 0.003 & 1.0 \\
\hline
\end{tabular}

With collimators in a fixed position with respect to the beam orbit, $\sim 99 \%$ of the beam halo energy is intercepted in the $60-\mathrm{m}$ long collimation section. About $1 \%$ is lost in the rest of the machine with the mean rate of $0.12 \mathrm{~W} / \mathrm{m}$. At several locations the beam loss is noticeably higher $(\sim 7 \mathrm{~W} / \mathrm{m})$, 
exceeding the tolerable rates. These 'hot' locations should be taken care of via local shielding. Using a local bump which keeps the beam at the edge of the primary collimators and close to the first secondary collimators during the cycle one can localize a majority of the beam loss in a 35$\mathrm{m}$ long region and to reduce the average loss in the ring to $0.05 \mathrm{~W} / \mathrm{m}$.
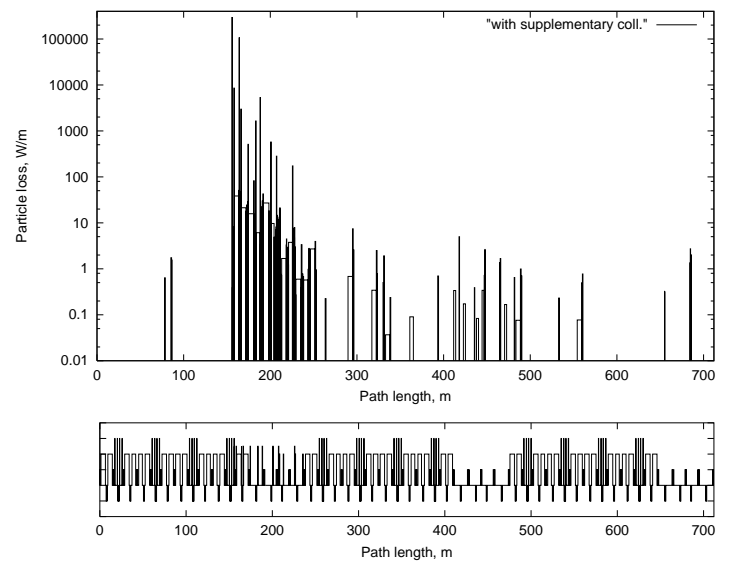

Figure 4: Beam loss distribution at the top energy.

The mechanical design of the collimators will be similar to those already built and installed in the Tevatron for Collider Run II [1]. The collimators consist of 2 pieces of stainless steel, $0.5 \mathrm{~m}$ long, welded together in an "L" configuration. $11.5 \mathrm{KW}$ of power can be removed from a single collimator by circulating low conductivity water through cooling channels on the outside of the collimator box (Fig. 5).

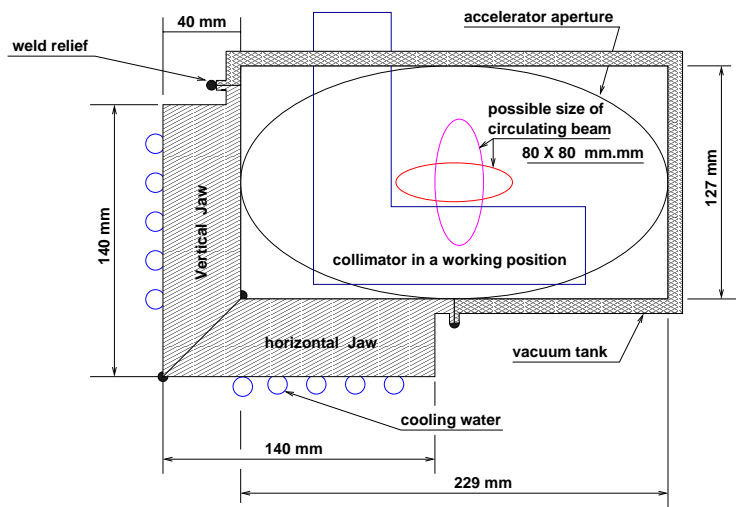

Figure 5: Secondary collimator cross section.

\section{SENSITIVITY ANALYSIS}

Closed orbit and betatron tune deviations during the cycle and from cycle to cycle change collimator offsets with respect to the circulating beam, phase advances between collimators and distance to the resonances. These affect a collimation efficiency. The results of a sensitivity analysis are shown in Tab. 4.
Table 4: Collimation system sensitivity analysis.

\begin{tabular}{|c|c|c|c|}
\hline $\begin{array}{c}\text { Source of efficiency } \\
\text { degradation }\end{array}$ & $\begin{array}{c}\text { Collimation } \\
\text { region }\end{array}$ & $\begin{array}{c}\text { Rest of the } \\
\text { ring }\end{array}$ & $\begin{array}{c}\text { Peak loss rate } \\
\text { in the ring }\end{array}$ \\
\hline collimators position, & $\mathrm{kW}$ & $\mathrm{kW}$ & $\mathrm{W} / \mathrm{m}$ \\
\hline secondary/supplementary & & & \\
\hline $1 \mathrm{~mm} / 3 \mathrm{~mm}$ & 11.497 & 0.023 & 9.5 \\
\hline $2 \mathrm{~mm} / 5 \mathrm{~mm}$ & 11.469 & 0.050 & 5.4 \\
\hline $3 \mathrm{~mm} / 6 \mathrm{~mm}$ & 11.457 & 0.062 & 10.6 \\
\hline orbit deviation & & & \\
\hline$-2 \mathrm{~mm}$ & 11.436 & 0.084 & 14.8 \\
0 & 11.470 & 0.050 & 5.4 \\
\hline $2 \mathrm{~mm}$ & 11.454 & 0.066 & 10.9 \\
\hline tune & & & 134.7 \\
\hline$\nu_{x} / \nu_{y}=12.443 / 11.351$ & 11.473 & 0.047 & 14.9 \\
$\nu_{x} / \nu_{y}=12.431 / 11.369$ & 11.460 & 0.060 & 127.7 \\
$\nu_{x} / \nu_{y}=12.407 / 11.407$ & 11.463 & 0.057 & 14.5 \\
$\nu_{x} / \nu_{y}=12.378 / 11.416$ & 11.477 & 0.043 & 14.5 \\
$\nu_{x} / \nu_{y}=12.363 / 11.421$ & 11.484 & 0.036 & \\
\hline
\end{tabular}

\section{BEAM ACCIDENT}

Let's consider a consequence to the machine components of an uncontrolled loss of a single pulse at $16 \mathrm{GeV}: 3 \times 10^{13}$ protons in Phase-I (1.2 MW) and $1 \times 10^{14}$ protons in PhaseII (4 MW). A beam after painting is assumed of a quasirectangular shape of a $7 \times 5 \mathrm{~mm}$ half-size. It hits a beam pipe at a grazing angle or a jaw of a secondary collimator. Initial temperature is assumed to be $27^{\circ} \mathrm{C}$.

An elliptical beam pipe dimensions are $5 \times 9$ inches with stainless steel walls 5 and 50 mils thick. Beam grazing angles are $\alpha=2,5$ and $10 \mathrm{mrad}$. Depending on the $\beta$-function, the maximum instantaneous temperature rise ranges from 33 to $38.5^{\circ} \mathrm{C}$ for a 5 -mils beam pipe and from 41 to $48^{\circ} \mathrm{C}$ for a 50-mils beam pipe for the Phase-I beam. At the PhaseII parameters, these numbers are roughly three times higher being still quite acceptable. Accidental loss of sequent pulses on a beam pipe exactly at the same location is unlikely.

A single $16-\mathrm{GeV}$ pulse of $3 \times 10^{13}$ protons hits normally a center of a $3 \mathrm{~cm}$ thick and $80 \mathrm{~cm}$ long stainless steel jaw of a secondary collimator. An instantaneous temperature rise in the jaw immediately after the pulse reaches its maximum value of $50^{\circ} \mathrm{C}$ at the beam axis at a 8 -cm depth in the jaw. At the Phase-II parameters, this value is roughly three times higher, that is quite acceptable. With an appropriate cooling system, several such pulses on the same collimator would be allowed.

\section{REFERENCES}

[1] Fermilab-TM-2136, The Proton Driver Design Study, (2001); http://fnalpubs.fnal.gov/archive/2001/tm/TM-2136.html

[2] I. S. Baishev, A. I. Drozhdin and N. V. Mokhov, "STRUCT Program User's Reference Manual”, SSCL-MAN-0034 (1994); http://www-ap.fnal.gov/ drozhdin/.

[3] N. V. Mokhov, "The MARS Code System User's Guide", Fermilab-FN-628 (1995); N. V. Mokhov and O. E. Krivosheev, "MARS Code Status", Fermilab-Conf00/181 (2000). http://www-ap.fnal.gov/MARS/.

[4] O.E. Krivosheev and N. V. Mokhov, Proc. of the 7th ICFA Mini-Workshop on Beam Halo and Scraping, Lake Como, WI, September 1999, p. 85. 